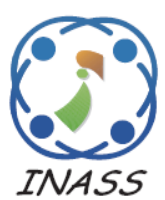

\title{
Ranking of Performance Measurement Systems for Smaller Businesses
}

\author{
Shahryar Sorooshian ${ }^{1 *} \quad$ Nor Filiani Aziz ${ }^{2} \quad$ Noor Azlinna Azizan ${ }^{3}$ \\ ${ }^{1}$ University of Gothenburg, Gothenburg, Sweden \\ ${ }^{2}$ Universiti Malaysia Pahang, Pahang, Malaysia \\ ${ }^{3}$ Prince Sultan University, Riyadh, Saudi Arabia \\ * Corresponding author's Email: sorooshian@gmail.com
}

\begin{abstract}
The Performance Measurement Systems (PMSs) seen as part of a factor that indicates the successful and unsuccessful company; especially in the Small and Medium Enterprises (SME's). The main objective is to analyze most suitable PMSs for Malaysian SMEs based on applicability. In the methodology, qualitative design with applied Analytic Hierarchy Process (AHP) is used. The expert panel is selected from practitioners linked with PMSs and SME's in Malaysia. The findings show the Balanced Scorecard (BSC) as first ranked of PMS in SMEs. Followed by BSC are the Theory of Constraints (TOC) and Result and Determinate Framework (RDF). The last three lowly ranked PMS which are the Medori and Steeple Framework (MDF), Dynamic Multi-dimensional Performance Framework (DMPF) and Holistic Performance Measurement Framework (HPMF). At the end of the study, the researcher makes the discussion and conclusion; it is also advised to improve and implement the suitable models in the Malaysian SME's for further success.
\end{abstract}

Keywords: Performance measurement system (PSM), Small and medium enterprise (SME), Analytic hierarchy process (AHP), Malaysia.

\section{Introduction}

A performance measurement system is a potential mechanism to foresee the success and failure of a company; if there are restrictions or barriers to implement a performance measurement system in the company's practice; these are detrimental to a company's orientation and profitability. This stresses the role of a performance measurement system to aid the company to succeed and evade failures. This study looks into the success and failure of Small and Medium Enterprises (SMEs) in Malaysia. In Malaysia, based on Portal Komuniti (KTAK), the SMEs failure rate is approximately 60\% [1]. According to Mohd Harif, Osman and Chee [2] most SMEs in Malaysia are plagued by management decision-making problems. To have effective and successful decision making, a performance measurement system is vital [3]. Basically, performance measurement system is an evaluation system to measure the organizational and/or company performance [4]; a performance measurement system has a big and important role in supporting the processes of decision making and evaluation [5].

According to Garengo, Biazzo, and Bititci [6], there are many types and tools of performance measurement systems practiced around the world. Each of the performance measurement system or tool has their own underlying theories, definition, features, strengths, and weaknesses. Each existing model has their own characteristics [7]; nevertheless, researchers still seek to prove the advantages and plus points of their models. Hence, the wide number of choices for performance measurement systems makes managers or anyone to decide on the performance measurement system get confused on which one is the suitable model for their organization. Based on the observation of the researchers, many SME managers in Malaysia are confused when it comes to deciding which performance measurement model to choose and implement in their company and/or organization. The PMS concept is a balanced 
and dynamic also holistic approach that uses different measurement and perspective indicators [8]. Generally, past studies found that PMS was detected to investigate the needs and criteria of PMS in large firms than lacks in the published research related with SMEs [9]. There are basic characteristics that identified in PMS versus SME organizations [6], as:

(1) Difficulty to establish SMEs in a performance measurement project.

(2) Failure to use performance measurement model or the use of wrong PMS models.

(3) Implementation of performance measurement that lacks a holistic indicator.

(4) SMEs have limited resources for data analysis.

The need for a suitable Performance Measurement System had attracted great interest of both practitioners (industrialists) and academicians; the lack of research and findings in SME performance measurement systems, especially in Asia, is quite alarming [10]. The lack of research on the performance measurement system is one of the major factors resulting in poor SME business decision making and high rate of bankruptcy. Although most Performance Measurement Systems have been designed and developed for large firms, some of them may be applicable to SMEs as well $[11,12]$. However, not all models can be used by SMEs as their performance measurement system. The researcher has seen a need to study the existing Performance Measurement Systems on their applicability and adoption in Malaysian Small and Medium Enterprises (SMEs).

To sum up, the main objectives of this research is to list the most suitable PMSs for Malaysian SMEs based on applicability. Meanwhile, to rank the existing PMSs' application, the researcher needs to list some of the conceptual criteria and alternatives. Lists of identified criteria of the PMS selection for practices in SMEs have been developed by Cocca and Alberti [13] as shown in Table 1.

In actuality, there are many alternative PSM models, but in this study only 15 models are weighed (listed in Table 2); these 15 models have their own strength and advantages to be implemented in Malaysian SME organizations. Meanwhile these are also the most popular models that have sufficient information and arguments published, suitable to be discussed and analysed for comparison manner; it was also discussed by previous researchers [8,14-19].

\section{Research methodology}

Data analysis method used in this study is Analytic Hierarchy Process (AHP). During the data collection of this research, researcher followed up with the main related government agencies of Malaysia, Small and Medium Enterprise Corporation (SME Corporation) and Malaysian Productivity Corporation (MPC); the experts from both agencies have great knowledge and experiences that are relevant to PMS and SMEs. The researcher used the judgemental sampling technique to set the panel of experts. 30 experts were invited for the interview; but fifteen of them could not complete the data collection process. Some of them did not complete the questionnaire; the other reason was deny the participation because of time constriction as experts of this study are mostly of top managers and high positioned personnel. Pointed, fifteen experts have been successfully completed the data collection phase. Saaty and Ozdemir [20] states that sample size of AHP is not fixed; numbers of respondents depend on the scenario of the problems and experts' viability. Wong and Li [21] agreed the AHP is not capable to use with large sampling size; it is not practical to use big sample size as it may result in high inconsistent result.

There are steps of mathematical calculations procedure in Analytic Hierarchy Process conducted as illustrated and explained by Ansah, Sorooshian, and Mustafa [22].

The pairwise comparison matrices of alternatives and criteria must be constructed based on the relevant the matrix A in the Eq. (1).

Table 1. List of applicability criteria

\begin{tabular}{|l|c|}
\hline \multicolumn{1}{|c|}{ Criteria } & Code \\
\hline Strategy Derived Operation of & $\mathrm{C} 2$ \\
\hline $\begin{array}{l}\text { Alignment Continuous } \\
\text { Strategy Vision }\end{array}$ & $\mathrm{C} 4$ \\
\hline $\begin{array}{l}\text { Construct Purpose/ Objective } \\
\text { Clearly }\end{array}$ & $\mathrm{C} 3$ \\
\hline $\begin{array}{l}\text { Stimulate } \\
\text { Improvement }\end{array}$ & $\mathrm{C} 5$ \\
\hline $\begin{array}{l}\text { Relevant and } \\
\text { Maintainable }\end{array}$ & $\mathrm{C} 6$ \\
\hline $\begin{array}{l}\text { Provide Accurate and Faster } \\
\text { Feedback }\end{array}$ & $\mathrm{C} 7$ \\
\hline $\begin{array}{l}\text { Balanced } \\
\text { Dimensional) }\end{array}$ & $\mathrm{C} 8$ \\
\hline Managerial Past Performance & $\mathrm{C} 9$ \\
\hline Planning Future Performance & $\mathrm{C} 10$ \\
\hline Stakeholder Consideration & $\mathrm{C} 11$ \\
\hline Promote Integration & $\mathrm{C} 12$ \\
\hline $\begin{array}{l}\text { Determinate Formulae and } \\
\text { Source }\end{array}$ & $\mathrm{C} 13$ \\
\hline $\begin{array}{l}\text { Easier to Understand and } \\
\text { Develop }\end{array}$ & \\
\hline
\end{tabular}


Table 2. Performance measurement system alternatives

\begin{tabular}{|c|c|c|c|}
\hline $\begin{array}{l}\text { Invention } \\
\text { Year }\end{array}$ & Model & Abbreviation & Code \\
\hline 1986 & $\begin{array}{l}\text { Theories of } \\
\text { Constraints }\end{array}$ & TOC & A1 \\
\hline 1989 & $\begin{array}{l}\text { Performance } \\
\text { Measurement } \\
\text { Matrix } \\
\end{array}$ & PMM & $\mathrm{A} 2$ \\
\hline 1991 & $\begin{array}{l}\text { Result and } \\
\text { Determinant } \\
\text { Framework }\end{array}$ & $\mathrm{RDF}$ & A3 \\
\hline 1991 & $\begin{array}{l}\text { European } \\
\text { Foundation for } \\
\text { Quality } \\
\text { Management } \\
\end{array}$ & EFQM & A4 \\
\hline 1991 & $\begin{array}{l}\text { SMART } \\
\text { Performance } \\
\text { Pyramid }\end{array}$ & SPP & A5 \\
\hline 1992 & $\begin{array}{l}\text { Balanced } \\
\text { Scorecard }\end{array}$ & BSC & A6 \\
\hline 1996 & $\begin{array}{l}\text { Integrated } \\
\text { Performance } \\
\text { Measurement } \\
\text { System for Small } \\
\text { Firms }\end{array}$ & IPMSSF & A7 \\
\hline 1997 & $\begin{array}{l}\text { Integrated } \\
\text { Performance } \\
\text { Measurement } \\
\text { System }\end{array}$ & IPMS & A8 \\
\hline 1997 & $\begin{array}{l}\text { Integrated } \\
\text { Dynamic } \\
\text { Performance } \\
\text { Measurement } \\
\text { System } \\
\end{array}$ & IDPMS & A9 \\
\hline 1998 & $\begin{array}{l}\text { Kanji's Business } \\
\text { Excellence } \\
\text { Model }\end{array}$ & KBEM & A10 \\
\hline 2000 & $\begin{array}{l}\text { Performance } \\
\text { Prism }\end{array}$ & $\mathrm{PP}$ & A11 \\
\hline 2000 & $\begin{array}{l}\text { Organizational } \\
\text { Performance } \\
\text { Measurement } \\
\end{array}$ & OPM & A12 \\
\hline 2000 & $\begin{array}{l}\text { Medori \& } \\
\text { Steeple's } \\
\text { Framework } \\
\end{array}$ & MSF & A13 \\
\hline 2003 & $\begin{array}{l}\text { Dynamic Multi- } \\
\text { dimensional } \\
\text { Performance } \\
\text { Framework }\end{array}$ & DMPF & A14 \\
\hline 2006 & $\begin{array}{l}\text { Holistic } \\
\text { Performance } \\
\text { Measurement } \\
\text { Framework }\end{array}$ & HPMF & A15 \\
\hline
\end{tabular}

$A=\left[\begin{array}{cccc}a_{11} & a_{12} & \cdots & a_{1 n} \\ a_{21} & a_{22} & \cdots & a_{2 n} \\ \vdots & \vdots & \cdots & \vdots \\ \vdots & \vdots & \cdots & \vdots \\ a_{n 1} & a_{n 2} & \cdots & a_{n n}\end{array}\right]$

where, $i, j=1,2, \ldots, n$,

$\mathrm{a}_{\mathrm{ij}}=1$ for $i=j$,

$\mathrm{a}_{\mathrm{ij}}=\frac{1}{\mathrm{a}_{\mathrm{ij}}}$ for $i \neq j$

The four-step calculation of the criteria weight and alternative local weight are selected from the existing matrices. Eqs. (2) until (5) are the steps [23, 24].

Step 1. Calculation of total data of each row:

$\mathrm{W}_{\mathrm{i}}=\sum_{j=1}^{n} \mathrm{a}_{\mathrm{ij}}, i=1,2, \ldots n$

Step 2. Normalization of local weight:

$\mathrm{A}_{\mathrm{i}}=\frac{\sum_{j=1}^{n} \mathrm{a}_{\mathrm{ij}}}{\sum_{k=1}^{n} \sum_{j=1}^{n} \mathrm{a}_{\mathrm{kj}}}, i=1,2, \ldots n$

Step 3. Calculation of Eigen Vector:

$$
\mathrm{C}_{\mathrm{i}}=\frac{1}{n}+\left(\mathrm{A}_{1}+\mathrm{A}_{2}+\cdots+\mathrm{A}_{\mathrm{n}}\right)
$$

Step 4. Alternatives global weight is synthesized from the local weights as Eq. (5) shows.

$$
A \times C=\left[\begin{array}{cccc}
a_{11} & a_{12} & \cdots & a_{1 n} \\
a_{21} & a_{22} & \cdots & a_{2 n} \\
\vdots & \vdots & \cdots & \vdots \\
\vdots & \vdots & \cdots & \vdots \\
a_{n 1} & a_{n 2} & \cdots & a_{n n}
\end{array}\right] \times\left[\begin{array}{c}
C_{1} \\
C_{2} \\
\vdots \\
C_{n}
\end{array}\right]
$$

\section{Results}

The majority of the respondents ages are 41-50 years old. $40 \%$ of respondents had work experiences more than 9 years, and $33.3 \%$ 7-8 years, although only one expert was working for 3-4 years. $46.7 \%$ of had a master's degree, $33.3 \%$ had a doctorate, and $20 \%$ had a degree.

The calculation of AHP started with the developing pair-wise comparison matrices. The first pair-wise comparison matrices are criteria versus 
Table 3. Pair-wise comparison matrices of criteria versus criteria

\begin{tabular}{|c|c|c|c|c|c|c|c|c|c|c|c|c|c|}
\hline criteria & C1 & C2 & C3 & C4 & C5 & C6 & C7 & C8 & C9 & C10 & C11 & C12 & C13 \\
\hline C1 & 1.00 & 6.00 & 5.00 & 7.00 & 0.50 & 5.00 & 0.33 & 6.00 & 6.00 & 6.00 & 5.00 & 6.00 & 5.00 \\
\hline C2 & 0.17 & 1.00 & 5.00 & 5.00 & 5.00 & 0.25 & 6.00 & 5.00 & 5.00 & 6.00 & 6.00 & 6.00 & 5.00 \\
\hline $\mathbf{C 3}$ & 0.20 & 0.20 & 1.00 & 7.00 & 6.00 & 5.00 & 6.00 & 9.00 & 6.00 & 5.00 & 5.00 & 5.00 & 6.00 \\
\hline $\mathbf{C 4}$ & 0.14 & 0.20 & 0.14 & 1.00 & 6.00 & 7.00 & 7.00 & 8.00 & 6.00 & 7.00 & 6.00 & 6.00 & 6.00 \\
\hline $\mathbf{C 5}$ & 2.00 & 0.20 & 0.17 & 0.17 & 1.00 & 6.00 & 5.00 & 6.00 & 5.00 & 0.33 & 6.00 & 5.00 & 5.00 \\
\hline $\mathbf{C 6}$ & 0.20 & 4.00 & 0.20 & 0.14 & 0.17 & 1.00 & 5.00 & 6.00 & 6.00 & 6.00 & 6.00 & 7.00 & 6.00 \\
\hline $\mathbf{C 7}$ & 3.00 & 0.17 & 0.17 & 0.14 & 0.20 & 0.20 & 1.00 & 7.00 & 5.00 & 6.00 & 0.50 & 0.50 & 8.00 \\
\hline $\mathbf{C 8}$ & 0.17 & 0.20 & 0.11 & 0.13 & 0.17 & 0.17 & 0.14 & 1.00 & 7.00 & 0.50 & 7.00 & 6.00 & 7.00 \\
\hline $\mathbf{C 9}$ & 0.17 & 0.20 & 0.17 & 0.17 & 0.20 & 0.17 & 0.20 & 0.14 & 1.00 & 5.00 & 7.00 & 7.00 & 0.50 \\
\hline $\mathbf{C 1 0}$ & 0.17 & 0.17 & 0.20 & 0.14 & 3.00 & 0.17 & 0.17 & 2.00 & 0.20 & 1.00 & 4.00 & 6.00 & 6.00 \\
\hline $\mathbf{C 1 1}$ & 0.20 & 0.17 & 0.20 & 0.17 & 0.17 & 0.17 & 5.00 & 0.14 & 0.14 & 0.25 & 1.00 & 7.00 & 5.00 \\
\hline $\mathbf{C 1 2}$ & 0.17 & 0.17 & 0.20 & 0.17 & 0.20 & 0.14 & 5.00 & 0.17 & 0.14 & 0.17 & 0.14 & 1.00 & 4.00 \\
\hline $\mathbf{C 1 3}$ & 0.20 & 0.20 & 0.17 & 0.17 & 0.20 & 0.17 & 0.13 & 0.14 & 2.00 & 0.17 & 0.20 & 0.25 & 1.00 \\
\hline
\end{tabular}

criteria that are measure thirteen criteria. Table 3 shows numerical preference ratings of criteria versus criteria from fifteen expert's (respondent). Meanwhile developing pair-wise comparison matrices of criteria versus criteria need the responds of lists the criteria's horizontally and vertically. It has the numerical ratings comparing the first horizontal of criteria with the second vertical criteria. Then the value of 1.00 is always assigned when comparing with same criteria. Table 3 shows the pair-wise comparison of criteria versus criteria. There 13 by 13 reciprocal matrixes from average paired comparison.

Through the pair-wise comparison matrices of criteria versus criteria, the process continues with developing pair-wise comparison of alternative versus alternative based on each criteria's stated. The rule of develop pair-wise comparison matrices similar with above. There are thirteen pair-wise comparison matrices of alternative versus alternative are created. Each table presented numerical preference based on the average of expert's evaluation for alternative versus alternatives between thirteen criteria's. As pointed, each table have difference preference value.

Normalization process is an important to get weight value of normalized matrix. Through this study researcher calculate normalization weight of criteria and alternatives from the pair-wise comparison matrices that are presented before. Continuous step of Analytic Hierarchy Process (AHP) is priority vector. The priority vector is obtained by average the sum of each row in the normalized matrix. Refer to normalization matrix researcher calculate the priorities vector each row of criteria's and alternatives. Researcher make a first calculation of priority vector of criteria with explain in the matrix the higher important value of criteria is
C4 with 0.1545. Experts (respondent) agreed stimulate continuous improvement give more important value of priority vector then followed with $\mathrm{C} 1$ is 0.1474 where criteria is strategy derived. Meanwhile the lower value of priority vector is C12 with average 0.0158. The experts (respondent) assume the determinate formulae and source is not an important for the criteria of performance measurement system.

The priority vector of alternatives based on criteria 1 (strategy derived): Higher priority vector is A6 that presented balanced scorecard as first ranked with 0.1890. Second is result and determinant framework (A3) with value 0.1378. Following by third and fourth ranked SMART performance pyramid (A5) 0.1040 and European foundation for quality management (A4) 0.1017 . Then the next rank following by theory of constraint (A1) 0.0977 , performance measurement matrix (A2) 0.0969, performance prism (A11) 0.0456, integrated performance measurement system (A8) 0.0448, integrated dynamic performance measurement system (A9) 0.0447, integrated performance measurement system for small firms (A7) 0.0394, kanji's business excellence method (A10) 0.0339, holistic performance measurement framework (A15) 0.0187 , organizational performance measurement (A13) 0.0156, medori and steeple framework (A13) 0.0152 , and dynamic multi-dimensional performance framework (A14) 0.0150 .

The priority vector of alternative based on criteria 2 (alignment operation of strategy vision): The first ranked is balanced scorecard (A6) 0.2021. Second is result and determinate framework (A3) 0.1373. Third is SMART performance pyramid (A5) 0.1057. Fourth ranked is performance measurement matrix (A2) 0.1026 then fifth ranked is European foundation 
for quality management (A4) 0.0918. Thus next ranked following by theory of constraint (A1) 0.0916 , performance prism (A11) 0.0525, integrated dynamic performance measurement system (A9) 0.0469, integrated performance measurement system (A8) 0.0434 , integrated performance measurement system for small firms (A7) 0.0382, kanji's business excellence model (A10) 0.0282, organizational performance measurement (A12) 0.0178, holistic performance measurement framework (A15) 0.0154, dynamic multi-dimensional performance framework (A14) 0.0140 , and last ranked is medori and steeple framework (A13) 0.0126 .

The priority vector of alternatives based on criteria 3 (construct purpose/ objective clearly): The first until fifth ranked is balanced scorecard (A6) 0.1783 , theory of constraint (A1) 0.1526 , result and determinate framework (A3) 0.1143, European foundation for quality management (A4) 0.1115 , and SMART performance pyramid (A5) 0.0987. Continuously with performance measurement matrix (A2) 0.0915 , performance prism (A11) 0.0463 , integrated performance measurement system for small firms (A7) 0.0387, integrated dynamic performance measurement system (A9) 0,0367, organizational performance measurement (A12) 0.0350 , integrated performance measurement system (A8) 0.0317, kanji's business excellence model (A10) 0.0261, dynamic multi- dimensional performance framework (A14) 0.0134, holistic performance measurement framework (A15) 0.0126, and medori and steeple framework (A15) 0.0126.

The priority vector of alternatives based on criteria 4 (stimulate continuous improvement): First ranked is balanced scorecard (A6) 0.1891. Second, third, fourth, and fifth ranked are performance measurement matrix (A2) 0.1510, SMART performance pyramid (A5) 0.1048, European foundation for quality management (A4) 0.1046 , and theory of constraint (A1) 0.0983. Next following section is result and determinate framework (A3) 0.0862 , organizational performance measurement (A12) 0.0450, performance prism (A11) 0.0429, integrated performance measurement system for small firms (A7) 0.0410, integrated performance measurement system (A8) 0.0390, kanji's business excellence model (A10) 0.0288, dynamic multidimensional performance framework (A14) 0.0273, integrated dynamic performance measurement system (A9) 0.0146, medori and steeple framework (A13) 0.0140, and holistic performance measurement framework.

The higher ranked for priority vector of alternatives based on criteria 5 (relevant and easier maintainable) is theory of constraint (A1) as first ranked with value 0.1850 . Then following by second ranked is balanced scorecard (A6) 0.1627. Third and fourth stated performance measurement matrix (A2) 0.1074 , and european foundation for quality management (A4) 0.0912. Fifth ranked is SMART performance pyramid (A5) 0.0810 . Following by performance prism (A11) 0.0696, result and determinate framework (A7) 0.0652, integrated performance measurement system for small firms (A7) 0.0541, integrated performance measurement system (A8) 0.0496, integrated dynamic performance measurement system (A9) 0.0447 , organizational performance measurement (A12) 0.0279, kanji's business excellence model (A10) 0.0210, medori and steeple framework (A13) 0.0162, holistic performance measurement framework (A15) 0.0132 and dynamic multi-dimensional performance framework (A14) 0.0113 .

To present priority vector of alternatives based on criteria 6 (provide accurate and faster feedback), the first ranked is theory of constraints (A1) 0.1777 then followed second ranked is balanced scorecard (A6) 0.1756. Third ranked is result and determinant framework (A3) 0.1173 meanwhile next ranked is performance measurement matrix (A2) 0.0864 . The fifth ranked is SMART performance pyramid (A5) 0.0782 and continued with European foundation for quality management (A4) 0.0777 , kanji's business excellence model (A10) 0.0624, integrated performance measurement system for small firms (A7) 0.0482, integrated dynamic performance measurement system (A9) 0.0425, integrated performance measurement system (A8) 0.0339, performance prism (A11) 0.0304, organizational performance measurement (A12) 0.0273, medori and steeple framework (A13) 0.0162, holistic performance measurement framework (A15) 0.0141, and dynamic multi-dimensional performance framework (A14) 0.0121.

The priority vector of alternatives based on criteria 7 (balanced/ multi-dimensional): Position show balanced scorecard (A6) 0.1848 back to first ranked of section. Then second ranked is theory of constraints (A1) 0.1471 followed by result and determinant framework (A3) 0.1308. Then fourth ranked is European foundation of quality management (A4) 0.0968. Fifth ranked is SMART performance pyramid (A5) 0.0939 next ranked are performance measurement matrix (A2) 0.0856, performance prism (A11) 0.0441, integrated performance measurement system (A8) 0.0406, integrated dynamic performance measurement system (A9) 0.0369, organizational performance measurement (A12) 0.0341, dynamic multidimensional performance framework (A14) 0.0212, 
medori and steeple framework (A13) 0.0121, and last ranked is holistic performance measurement framework (A15) 0.0119 .

The priority vector of alternatives based on criteria 8 (managerial past performance) that presented balanced scorecard (A6) 0.1845 as first ranked. Second ranked is European foundation for quality management (A4) 0.1245 the followed by third ranked is result and determinant framework (A3) 0.1214 . Fourth and fifth ranked show theory of constraints (A1) 0.1168 and performance measurement matrix (A2) 0.1063. Continuously with integrated performance measurement system (A8) 0.0669 , SMART performance pyramid (A5) 0.0554, kanji's business excellence model (A10) 0.0532, integrated performance measurement system for small firms (A7), integrated dynamic performance measurement system (A9) 0.0286 , organizational performance framework (A12) 0.0254, dynamic multi-dimensional performance framework (A14) 0.0229, medori and steeple framework (A13) 0.0214, holistic performance measurement framework (A15) 0.0143 , and performance prism (A11) 0.0138 .

The priority vector of alternatives based on criteria 9 (planning future performance): The first ranked is balanced scorecard (A6) 0.2015 then second ranked is result and determinant framework (A3) 0.1603. Third ranked is performance measurement matrix (A2) 0.1199. Fourth and fifth ranked are integrated performance measurement system (A8) 0.0915 and theory of constraints (A1) 0.0871 . Subsequently European foundation for quality management (A4) 0.0638, SMART performance pyramid (A5) $0.0588, \quad$ integrated performance measurement system for small firms (A7) 0.0668 , kanji's business excellence model (A10) 0.0472 , integrated dynamic performance measurement system (A9) 0.0403 , organizational performance measurement (A12) 0.0165 , medori and steeple framework (A13) 0.0160, holistic performance measurement framework (A15) 0.0143, performance prism (A11) 0.0165, and dynamic multi- dimensional performance framework (A14) 0.1223 .

The priority vector of alternatives based on criteria 10 (stakeholder consideration): First position ranked is balanced scorecard (A6) 0.1794 followed by performance measurement matrix (A2) 0.1107 as second ranked. Third ranked is European foundation for quality management (A4) 0.1085 . While the fourth and fifth ranked are integrated dynamic performance measurement system (A9) 0.0988 and theory of constraints (A1) 0.0982 . The next ranked is SMART performance pyramid (A5) 0.0969, result and determinant framework (A3) 0.0709, integrated performance measurement system for small firms (A7) 0.0704, medori and steeple framework (A13) 0.0405 , dynamic multi- dimensional performance framework (A14) 0.0266, kanji's business excellence model (A10) 0.0261, performance prism (A11) 0.0261 , integrated performance measurement system (A8) 0.0197, organizational performance framework (A12) 0.0180, and holistic performance measurement framework (A15) 0.0111.

The priority vector of alternatives based on criteria 11 (promote integration): During this table performance measurement matrix (A2) won the first position ranked with value 0.1926 . After that second ranked is balanced scorecard (A6) 0.1514 then followed by result and determinant framework (A3) 0.1086 . Fourth ranked is theory of constraints (A1) 0.0930. Continuously with fifth till end ranked are integrated performance measurement system for small firms (A7) 0.0918, European foundation for quality management (A4) 0.0775, kanji's business excellence model (A10) 0.0665 , SMART performance pyramid (A5) 0.0465, integrated dynamic performance measurement system (A9) 0.0371, medori and steeple framework (A13) 0.0343, performance prism (A11) 0.0291, integrated performance measurement system (A8) 0.0251, organizational performance measurement (A12) 0.0229, holistic performance measurement framework (A15) 0.0123, and dynamic multidimensional performance framework (A14) 0.0110 .

The priority vector of alternative based on criteria 12 (determinate formulae and source): Balanced scorecard (A6) also presented first ranked position with value 0.1758 . The second ranked is result and determinant framework (A3) 0.1296 then third ranked present European foundation for quality management (A4) 0.1296 take the top three position. Subsequently the fourth and fifth ranked are performance measurement matrix (A2) 0.1093 and theory of constraints (A1) 0.1054. Meanwhile the next ranked is SMART performance pyramid (A5) 0.0607, integrated dynamic performance measurement system (A9) 0.0586, integrated performance measurement system (A8) 0.04800, organizational performance measurement (A12) 0.0442 , integrated performance measurement system for small firms (A7) 0.0399, dynamic multidimensional performance framework (A14) 0.0267, performance prism (A11) 0.0249, medori and steeple framework (A13) 0.0172, kanji's business excellence model (A10) 0.0169, and holistic performance measurement framework (A15) 0.0122 .

The priority vector of alternatives based on criteria 13 (easier to understand and develop): First ranked is balanced scorecard (A6) 0.2059 then 
second ranked is result and determinant framework (A3) 0.1548 . Third ranked is theory of constraints (A1) 0.1029 while performance measurement matrix (A2) 0.0740 as the fourth position. Next ranked is SMART performance pyramid (A5) 0.0711 be the fifth ranked. Thus the ranking followed by medori and steeple framework (A13) 0.0703, integrated dynamic performance measurement system (A9) 0.0675 , integrated performance measurement system (A8) 0.0511, performance prism (A11) 0.0476, integrated performance measurement system for small firms (A7) 0.0433, European foundation performance measurement (A4) 0.0432, dynamic multi- dimensional performance framework (A14) 0.0237 , organizational performance measurement (A12) 0.0176, kanji's business excellence model (A10) 0.0164, and holistic performance measurement framework (A15) 0.0107 .

The overall priorities vector is relationship between priorities weights of criteria with priority weight of alternative based on thirteen criteria's. The result of overall priorities vector showed in the Table 4. The table shows the analysis of overall priorities vector. Hence, the higher overall priority weight is balanced scorecard with overall priority value 0.1466 $(18.33 \%)$. Second is Theory of Constraint with value 0.1221 (12.58\%). Third ranked result and determinate framework is $0.1093(11.28 \%)$ then fourth ranked performance measurement matrix is $0.1073(10.94 \%)$. Followed by European foundation for quality management is $0.0924(9.60 \%)$, SMART Performance Pyramid is 0.0726 (9.18\%), integrated performance measurement system for small firms is $0.0454(4.54 \%)$, performance prism is 0.0443 $(4.43 \%)$, integrated performance measurement system is $0.0413(4.13 \%)$, integrated dynamic performance measurement system is $0.0404(4.04 \%)$, kanji's business excellence model is 0.0337 (3.37\%), organizational performance measurement is 0.0277 $(2.77 \%)$, medori and steeple framework is 0.0171 $(1.71 \%)$, dynamic multi-dimensional performance framework is $0.0168(1.68 \%)$, and last ranked of overall priority vector is holistic performance measurement framework with $0.01402(1.42 \%)$.

Thus the results show balanced scorecard appeared to be the first ranked alternative. The difference of balanced scorecard with theory of constraints as second ranked is $5.75 \%$. There are big gaps of differential of ranked. It is show the bigger evaluation agreed that balanced scorecard as a first choice of performance measurement system for Malaysian SMEs.
Table 4. Analysis of overall priorities vector

\begin{tabular}{|c|c|c|c|}
\hline 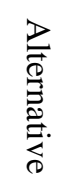 & Overall priority weight & Percentages (\%) & $\begin{array}{l}\text { त्र } \\
\text { 总 }\end{array}$ \\
\hline A1 & 0.125828621 & $12.58 \%$ & 2 \\
\hline $\mathrm{A} 2$ & 0.109408172 & $10.94 \%$ & 4 \\
\hline A3 & 0.112782069 & $11.28 \%$ & 3 \\
\hline A4 & 0.095984583 & $9.60 \%$ & 5 \\
\hline A5 & 0.091792642 & $9.18 \%$ & 6 \\
\hline A6 & 0.183300775 & $18.33 \%$ & 1 \\
\hline A7 & 0.045362426 & $4.54 \%$ & 7 \\
\hline A8 & 0.041302592 & $4.13 \%$ & 9 \\
\hline A9 & 0.040367735 & $4.04 \%$ & 10 \\
\hline A10 & 0.033735028 & $3.37 \%$ & 11 \\
\hline A11 & 0.044319541 & $4.43 \%$ & 8 \\
\hline A12 & 0.027667037 & $2.77 \%$ & 12 \\
\hline A13 & 0.017178211 & $1.72 \%$ & 13 \\
\hline A14 & 0.016797957 & $1.68 \%$ & 14 \\
\hline A15 & 0.014172611 & $1.42 \%$ & 15 \\
\hline
\end{tabular}

\section{Conclusion}

According to the results, the applicable PMS model for Malaysian SMEs is the balanced scorecard. As has been discussed, experts agreed that the balanced scorecard (BSC) is the first ranked performance measurement system for Malaysian SMEs. Uniqueness of BSC has attracted many experts to choose the BSC with high scale preference rating compared to the other models. There has been a lot of argument to compare PMS but most of expert preferred BSC which focuses to achieve strategic goals [24]. BSC is also a model that focuses and emphasizes strategies and objectives clearly. It is a model that looks at the future missions and reviews previous achievement.

Followed by BSC is the Theory of Constraints (TOC). Experts believed that the second ranked model, TOC, is closely related to the constraints. TOC focuses more on the constraints and managerial aspects but many SMEs in Malaysia adopts TOC as an evaluation system for their businesses. The experience stated that TOC is a familiar system in Malaysian businesses. However, the ability of the TOC to be second ranked is not clear because TOC does not cover both financial and non-financial measurement indicators. Simply, TOC has own its strength, yet they do not match with BSC's. 
Generally, TOC focuses on the strengths of constraints only. However, in this study, researcher tried to cover both financial and non-financial measures. That means the whole business indicators variables.

Result and Determinate Framework (RDF) has been realized as the third ranked PMS model. RDF is a model that focuses on the results and determinants with lagging and leading factors to measure the performance of an organization or operation. RDF is a similar model with BSC; the difference is that RDF only focuses on the financial and organizational strategy. The disadvantage of RDF to not consolidate other non-financial indicators fails it to emulate BSC. To make it clearer, the result was showed that top three ranked of PMS for Malaysian SMEs as are BSC, TOC, and RDF sequentially. However, the hierarchy rank is followed by Performance Measurement Matrix (PMM), European Foundation for Quality Management (EFQM), SMART performance pyramid (SMART PP), and Integrated Performance Measurement System for Small Firms (IPMSSF), Performance Prism (PP), Integrated Performance Measurement System (IPMS), Integrated Dynamic Performance Measurement System (IDPMS), Kanji's Business Excellence Model (KBEM), and Organizational Performance Measurement (OPM) sequentially based on the ranks analysed.

The last three lowly ranked PMS, which are the Medori and Steeple Framework (MDF), Dynamic Multi-dimensional Performance Framework (DMPF) and Holistic Performance Measurement Framework (HPMF), are not widely responded to relative to models that have high scores. The disadvantages of these models have convinced the experts not to choose this model to measure or evaluate the performance of Malaysian SMEs. Commonly, these three models are not suitable to be practiced in the Malaysian SMEs. Based on the findings, experts normally do not perceive the last three lowly ranked models as a suitable model to be implemented in the Malaysian SMEs to maintain the overall measurement and management of the existing ones. The real scenario worries and causes the experts to cautious in choosing this model as better alternatives. Experts need to look farther to ensure each measurement to be in control and still maintain or improve the profitability and success of the company. The discussion concluded that PMS model is an important indicator for the company [25]; so the applicable PMS need to be clearly and company need to choose the best choice PMS to maintain performances [26] and also their profitability.

\section{References}

[1] N.A. Ahmad and P.S. Seet, "Dissecting Behaviour Associated with Business Failure: A Qualitative Study of SME Owners in Malaysia and Australia", Asian Social Science, Vol.5, No. 9, pp.98-104, 2009.

[2] M. Mohd-Harif, H. Osman, and H.H. Chee, "Financial Management Practices: An In- Depth Study among the CEOs of Small and Medium Enterprises (SME's)", International Review Business Research Papers, Vol. 6, No. 6, pp. 1335, 2010.

[3] N.M. Mustapha, S. Sorooshian, and N.A. Azizan, "Categorization of Indicators for Performance of Small and Medium Enterprises", In: Proc. of the first GCC International Conference on Industrial Engineering and Operations Management, 2019

[4] N.M. Mustapha, S. Sorooshian, and N.A. Azizan, "Exploring Performance Indicators of Small and Medium Enterprises", In: Proc. of the first GCC International Conference on Industrial Engineering and Operations Management, 2019.

[5] A. Neely, C. Adams, and M. Kennerley, "The performance prism: The scorecard for measuring and managing business success", Cranfield School of Management, Vol.1, No.13, 2002.

[6] P. Garengo, S. Biazzo, and U.S. Bititci, "Performance measurement systems in SMEs: A review for a research agenda", International Journal of Management Reviews, Vol.7, No.1, pp.25-47, 2005.

[7] S. Sorooshian, N.F. Aziz, A. Ahmad, S.N. Jubidin, and N.M Mustapha, "Review on performance measurement systems", Mediterranean Journal of Social Sciences, Vol.7, No.1, pp.123-132, 2016.

[8] M. Jamil and R. Mohamed, "Performance measurement system (PMS) in small medium enterprise (SMES): A practical modified framework", World Journal of Social Sciences, Vol.1, No.3, pp. 200-212, 2011.

[9] M. Hudson, A. Smart, and M. Bourne, "Theory and practice in SME performance measurement systems", International Journal of Operations \& Production Management, Vol.21, pp.1067-1115. 2001.

[10] S. Sorooshian and A. Anvari, "Performance Analysis: lack of Research in Asian Small and Medium Enterprise Sector", Advances in Asian Social Science, Vol.1, No.3, pp.312. 2012.

[11] H. Jungman, J. Okkonen, T. Rasila, and M.Seppa, "Use of Performance in V2C activity", 
Benchmarking: An International Journal, Vol. 11, No. 2, pp. 175-189, 2004.

[12] $\mathrm{D}$. $\mathrm{Wu}$, "Measuring performance in small and medium enterprises in the information \& communication technology industries", A Thesis Submitted in Fulfilment of the Requirements for the Degree of Doctorate of Philosophy, RMIT University, pp.209. 2009.

[13] P.Cocca and M. Alberti, "A framework to assess performance measurement systems in SMEs", International Journal of Productivity and Performance Management, Vol. 59, No. 2, pp. 186-200, 2009.

[14] P. Taticchi, F. Tonelli, and L. Cagnozzo, "Performance measurement and management: A literature review and a research agenda", Measuring Business Excellence, Vol. 14, No. 1, pp. 4-18, 2010.

[15] G.P. Kurien and M.N. Qureshi, "Study of performance measurement practices in supply chain management", International Journal of Business, Management and Social Sciences, Vol.2, No.4, pp.19-34, 2011.

[16] T. Sriwidadi, "Integrated Performance Measurement System for SME and Management Control System" BINUS University, Vol.9, 2012.

[17] D. Zeglat, W. Airawabdeh, F. Almadi, and F. Shrafat, "Performance Measurement Systems: Stages of Development Leading to Success", Interdisciplinary Journal of Contemporary Research in Business, Vol. 4, No. 7, pp.440-448, 2012.

[18] K. Lisiecka and E. Czyz-Gwiazda, "Performance Measurement Models Comparative Review", In: Proc. of the 57th EOQ Congress: Quality Renaissance-Cocreating a Viable Future, pp.900-904, 2013.

[19] N.M. Mustapha, S. Sorooshian, and N.A. Azizan, "Performance Measures for Developing the Performance Measurement System: Systematic Literature Review Approach", Quality - Access to Success, Vol. 18 No. 156, pp. 57-64, 2017.

[20] T.L. Saaty and M.S. Ozdemir, "How many judges should there be in a group?", Annuals of Data Science, Vol.1, pp.359-368, 2014.

[21] J.K.W. Wong and H. Li, "Application of the analytic process (AHP) in multi-criteria analysis of the selection of intelligent building systems", Building and Environment, Vol.43, No.1, pp.108-125, 2008.

[22] R.H. Ansah, S. Sorooshian, and S. Mustafa, "Analytic Hierarchy Process Decision Making Algorithm", Global Journal of Pure and Applied
Mathematics, Vol. 11, No. 4, pp. 2403-2410, 2015.

[23] N.F. Aziz, S. Sorooshian, and F. Mahmud, "MCDM-AHP method in decision makings", ARPN Journal of Engineering and Applied Sciences, Vol.11, No. 11, pp.7217-7220, 2016.

[24] S. Sorooshian, "Study on unbalanceness of the balanced scorecard", Applied Mathematical Sciences, Vol.8, No.84, pp. 4163-4169, 2014.

[25] S. Sorooshian, "Adaptation of a Business Performance Measurement System for Malaysian Smaller Enterprises System for Malaysian Smaller Enterprises", Quality - Access to Success, Vol.18, No.157, pp. 124-131, 2017.

[26] N.M. Mustapha and S. Sorooshian, "SME performance measurement: A technical review of Malaysia”, International Journal of Innovative Technology and Exploring Engineering, Vol. 8, No. 8, pp. 1808-1812, 2019. 